\title{
Hyperphenylalaninaemia and outcome in intravenously fed preterm neonates
}

\author{
A Lucas, B A Baker, R M Morley
}

\begin{abstract}
Hyperphenylalaninaemia is likely to have occurred in many infants fed the intravenous amino acid solution Vamin 9. In this study of 336 preterm infants plasma phenylalanine was measured weekly during their hospital stay. Reference data on plasma phenylalanine were prepared for 243 infants who did not receive Vamin. Only $1 \%$ of these infants had a peak plasma phenylalanine concentration greater than $150 \mu \mathrm{mol} / \mathrm{l}$ (maximum 202 $\mu \mathrm{mol} / \mathrm{l})$ compared with $23 \%$ in 93 infants fed Vamin 9, seven of whom had concentrations $>\mathbf{3 0 0} \mu \mathrm{mol} / \mathrm{l}$ (maximum 704 $\mu \mathrm{mol} / \mathrm{l})$. High concentrations only occurred when the total energy to protein energy ratio in the intravenous solutions decreased to less than $8 \cdot 5: 1$ and always occurred with a ratio less than $6 \cdot 5: 1$, implying that hyperphenylalaninaemia may be minimised with an intravenous energy intake of greater than $34 \mathrm{kcal}$ $(142 \mathrm{~kJ}) / \mathrm{g}$ protein. Nevertheless, follow up at 18 months post-term showed that increased plasma phenylalanine in this instance was not associated with any impairment of the Bayley mental development index (or subscales including fine motor, cognitive, or language development), the psychomotor development index, or the social maturity quotient. Thus, despite theoretical concern, an adverse outcome after hyperphenylalaninaemia induced by intravenous feeding has not been observed.

(Arch Dis Child 1993; 68: 579-583)
\end{abstract}

Intravenous nutrition has been a major advance in neonatal intensive care. The clinical safety of intravenous feeding solutions, however, has been subject to continued vigilance. Over the past five years there has been a number of reports of increased plasma phenylalanine concentrations in infants fed certain intravenous amino acid solutions, notably Vamin 9 (Kabi), which has been much used in Britain for term and preterm neonates. ${ }^{1-5}$ As increased plasma phenylalanine in phenylketonuria is well known to be associated with long term neurological damage ${ }^{6}$ it has been argued, by analogy, that hyperphenylalaninaemia in intravenously fed infants could damage the developing brain.

We have studied plasma phenylalanine concentrations in the early weeks after birth in 336 intensively monitored preterm infants, survivors of whom have had neurodevelopmental assessments at 18 months post-term. These data have been used to derive reference concentrations for plasma phenylalanine, to quantify the prevalence and severity of hyperphenylalaninaemia in infants fed intravenously with Vamin 9, to explore the relation of increased plasma phenylalanine with later developmental scores, and to examine whether attention to the design of intravenous feeding regimens, notably the total energy to protein energy (TE:PE) ratio, could minimise disturbances in plasma concentrations of this amino acid.

\section{Subjects and methods}

A total of 336 preterm infants weighing less than $1859 \mathrm{~g}$ at birth were studied in five centres (Cambridge, Ipswich, Kings Lynn, Norwich, and Sheffield). The infants were taking part in a larger long term randomised outcome study on the effects of early diet. ${ }^{78}$

Venous blood specimens were obtained for amino acid analyses in the morning at the time of clinically indicated sampling. Specimens were collected in cooled tubes and the plasma was separated and placed in $-20^{\circ} \mathrm{C}$ storage within 30 minutes. Samples were obtained weekly until the infant was discharged or attained a body weight of $2000 \mathrm{~g}$, whichever was the sooner. All plasma samples were stored at $-20^{\circ} \mathrm{C}$ until analysed.

After thawing at room temperature samples were gently vortexed before the aliquots for analysis were removed. A volume of $110 \mu \mathrm{l}$ was then withdrawn and transferred to a round bottomed polystyrene tube, together with 92 $\mu l 0.2 \mathrm{M}$ lithium citrate loading buffer $(\mathrm{pH}$ $2 \cdot 2$ ) containing the norleucine internal standard $(250 \mathrm{nmol} / \mathrm{ml})$ and the sulphosalicylic acid deproteiniser $(2.5 \mathrm{mg} / 100 \mu \mathrm{l}$ of $0.2 \mathrm{M}$ lithium citrate. The sample was vortexed and allowed to stand at $4^{\circ} \mathrm{C}$ for one hour after which it was centrifuged at $2500 \mathrm{rpm}$ for 15 minutes, also at $4^{\circ} \mathrm{C}$. The supernatant was decanted into a microfilter system (Anachem Ltd, Cat No BAS MF5500) using a $0.2 \mu \mathrm{m}$ regenerated cellulose membrane filter, and centrifuged again for 15 minutes at $2500 \mathrm{rpm}\left(4^{\circ} \mathrm{C}\right)$. A final sample volume of 100 $\mu l$ filtrate was analysed in an LKB Alpha Plus 4151 analyser using a physiological fluids programme with the lithium citrate buffer ninhydrin system. The results were processed by an in line Hewlett-Packard 3392A integrator.

Of the 336 infants studied, 243 never received intravenous amino acids. The 93 infants requiring an intravenous amino acid 
solution were given Vamin 9. Table 1 gives demographic and clinical data collected for these two groups of infants.

The detailed clinical and demographic information collected allowed calculation of the TE:PE ratio of nutrients consumed by the intravenous and enteral routes during the course of intravenous nutrition. These data were used to relate the TE:PE ratio to the peak plasma phenylalanine concentration.

At 18 months post-term surviving infants were invited for follow up which included application of the Bayley scales for mental and psychomotor development. ${ }^{9}$ Language, fine motor and cognitive subscales were also calculated from the Bayley mental development scale. ${ }^{10}$ The questionnaire based Vineland social maturity scales ${ }^{11}$ were administered to the care giver and a social quotient was derived from the equation: (social age)/(age from expected date of delivery) $\times 100$.

This follow up was conducted on 278 infants, representing a $95 \%$ follow up rate of survivors.

Statistical analyses included the $\chi^{2}$ test, Student's $t$ test, and multiple regression analysis to examine the relation between peak plasma phenylalanine concentration and developmental outcome after adjusting for potentially confounding factors.

\section{Results}

Table 1 shows, as expected, that infants who received Vamin had a lower mean birth weight and gestational age and required more ventilation than those who did not require intravenous amino acids. Those receiving Vamin were given it for a median of 10 days (table 1).

Reference centile data were compiled for plasma phenylalanine in the 243 infants who did not receive intravenous amino acids. Exploratory analysis showed no significant difference between values in the gestational age groups 25-28 weeks, 29-32 weeks, and 33-36 weeks. These three groups were therefore combined (see table 2). There was a slight decrease in the values over the first two weeks which then stabilised and values remained constant during the period of study (up to $2000 \mathrm{~g}$ body weight).

When the maximum (peak) plasma phenylalanine concentration was taken for each infant in this group the 95th centile was $102 \mu \mathrm{mol} / 1$ (table 3). Only three values were above 150 (99th centile), and the highest of these was 202 $\mu \mathrm{mol} / 1$.

Table 1. Clinical and demographic characteristics of preterm infants who did or did not receive intravenous amino acids (Vamin 9)

\begin{tabular}{lcc}
\hline & & $\begin{array}{c}\text { Did not receive } \\
\text { intravenous } \\
\text { amino acids } \\
(n=243)\end{array}$ \\
\hline $\begin{array}{l}\text { Mean (SE) birth weight (g) } \\
(n=93)\end{array}$ & $1185(35)$ & $1426(17)^{\star}$ \\
$\begin{array}{l}\text { Mean (SE) gestation (weeks) } \\
\% \text { (No) male }\end{array}$ & $29 \cdot 0(0 \cdot 3)$ & $31 \cdot 3(0 \cdot 2)^{\star}$ \\
$\%$ (No) ventilated & $54(50)$ & $49(119)$ \\
$\geqslant 1$ day & $81(75)$ & $31(74)^{\star}$ \\
$\geqslant 7$ days & $52(48)$ & $7(17)^{\star}$ \\
$\%$ (No) with Apgar score <4 at five minutes & $9(8)$ & $7(16)$ \\
Median (quartiles) days receiving Vamin 9 & $10(6,25)$ & - \\
\hline
\end{tabular}

${ }^{\star} \mathrm{p}<0.001$
Table 2 Reference centiles (unsmoothed) for plasma phenylalanine ( $\mu \mathrm{mol} / \mathrm{)}$ ) in 243 infants who never received intravenous amino acids. Infants 25-36 weeks' gestation

\begin{tabular}{|c|c|c|c|c|c|}
\hline \multirow{2}{*}{$\begin{array}{l}\text { Postnatal } \\
\text { age (weeks) }\end{array}$} & \multicolumn{2}{|c|}{ Centile } & \multirow[b]{2}{*}{50} & \multirow[b]{2}{*}{90} & \multirow[b]{2}{*}{95} \\
\hline & 5 & 10 & & & \\
\hline $\begin{array}{c}1-2 \\
3-4 \\
>5^{\star}\end{array}$ & $\begin{array}{l}36 \\
29 \\
30\end{array}$ & $\begin{array}{l}41 \\
34 \\
35\end{array}$ & $\begin{array}{l}62 \\
50 \\
48\end{array}$ & $\begin{array}{l}91 \\
73 \\
70\end{array}$ & $\begin{array}{l}100 \\
84 \\
79\end{array}$ \\
\hline
\end{tabular}

Phenylalanine values for infants of different gestational age bands combined as there was no trend with gestational age. ^From week 5 to discharge at $2000 \mathrm{~g}$ there was no trend in plasma phenylalanine concentration with age, regardless of plasma phenylal
gestational age.

Table 3 Peak plasma phenylalanine concentrations ( $\mu \mathrm{mol} / \mathrm{l})$ in infants who did or did not receive Vamin 9

\begin{tabular}{llllll} 
& \multicolumn{2}{l}{ Centile } & & & \\
\cline { 2 - 6 } & 5 & 10 & 50 & 90 & 95 \\
$\begin{array}{l}\text { Received Vamin } \\
(\mathrm{n}=93)\end{array}$ & 42 & 52 & 86 & 218 & 415 \\
$\begin{array}{c}\text { Did not receive Vamin } \\
(\mathrm{n}=243)\end{array}$ & 42 & 46 & 66 & 96 & 102
\end{tabular}

*Five highest values: 407, 440, 473, 539, $704 \mu \mathrm{mol} / 1$. tOnly $1 \%$ (three values) in excess of $150 \mu \mathrm{mol} / 1$ compared with $23 \%$ (21 values) in the Vamin group $(\mathrm{p}<0.0001)$.

In contrast, high values were often seen in infants fed Vamin 9 (table 3); $40 \%$ of values (37/93) were greater than $100 \mu \mathrm{mol} / 1(95 \%$ centile for reference population) and $23 \%$ (21/93) were greater than $150 \mu \mathrm{mol} / 1$ (99th centile; see table 3 ). The $95 \%$ centile for this group was $415 \mu \mathrm{mol} / \mathrm{l}$, over four times that for the $95 \%$ centile value in the reference population. The highest value recorded was 704 $\mu \mathrm{mol} / \mathrm{l}$ (table 3 ).

We investigated whether the higher values in the group fed with Vamin could be explained by the fact that this group tended to contain the smaller, sicker infants. Seventeen infants who did not receive intravenous amino acids, however, had respiratory disease requiring ventilation for one week or more and $23 \%$ weighed less than $1200 \mathrm{~g}$ at birth (used to define the high risk low birthweight stratum in our multicentre study), yet none of these infants had peak plasma phenylalanine concentrations greater than $202 \mu \mathrm{mol} / \mathrm{l}$ and most had concentrations less than $100 \mu \mathrm{mol} / \mathrm{l}$. Regression analysis was also used to adjust the difference in plasma phenylalanine concentrations between the Vamin and non-Vamin fed groups for potential confounders, including birth weight, gestation, and days of ventilation. The adjusted difference between groups was little different to that seen in the raw data and was equally significant. Finally, in all instances when a Vamin fed infant developed a plasma phenylalanine concentration greater than 200 $\mu \mathrm{mol} / \mathrm{l}$ (above the reference range), this only occurred while the Vamin was being infused.

The relation of TE:PE ratio with peak plasma phenylalanine concentration was explored in 42 infants who received more than $1 \mathrm{~g}$ of intravenous protein each day for the 72 hours before the time of their peak plasma phenylalanine concentration. Table 4 shows that infants with peak plasma phenylalanine concentrations less than $100 \mu \mathrm{mol} / \mathrm{l}$ had the highest TE:PE ratios and those with peak 
Table 4 Peak plasma phenylalanine concentrations in relation to mean TE:PE ratio and mean (SE) protein intake

\begin{tabular}{|c|c|c|}
\hline $\begin{array}{l}\text { Peak plasma } \\
\text { phenylalanine } \\
\text { ( } \mu \text { moll) }\end{array}$ & $\begin{array}{l}\text { Mean (SE) } \\
\text { TE:PE ratio }\end{array}$ & $\begin{array}{l}\text { Mean } \\
\text { protein } \\
\text { intake (g/day) }\end{array}$ \\
\hline $\begin{array}{l}\text { (a) }<100(n=12) \\
\text { (b) } 100-150(n=11) \\
\text { (c) }>150(n=19)\end{array}$ & $\begin{array}{l}9 \cdot 7(0 \cdot 9) \\
6 \cdot 3(0 \cdot 4) \\
5 \cdot 9(0 \cdot 2)\end{array}$ & $\begin{array}{l}1 \cdot 9(0 \cdot 2) \\
2 \cdot 6(0 \cdot 3) \\
2 \cdot 6(0 \cdot 2)\end{array}$ \\
\hline
\end{tabular}

For TE:PE ratio: (a) $v$ (b), $\mathrm{p}<0.005$; (b) $v$ (c), $\mathrm{p}<0.0001$. For protein intake: (a) $v$ (b), $\mathrm{p}>0 \cdot 1$; (a) $v$ (c), $\mathrm{p}<0 \cdot 01$.

Table 5 Lack of relation between peak neonatal plasma phenylalanine and developmental outcome at 18 months

\begin{tabular}{lrl} 
Test & $t$ Value $^{*}$ & $p$ Valuet \\
\hline Bayley motor development index & 0.29 & 0.77 \\
Bayley mental development index & -0.68 & 0.50 \\
Subscales & & \\
$\quad$ Language & -0.08 & 0.94 \\
$\quad$ Fine motor & -0.64 & 0.53 \\
$\quad$ Cognitive & -1.05 & 0.30 \\
Social maturity quotient & 0.12 & 0.90 \\
\hline
\end{tabular}

* Negative sign signifies lower score with higher peak phenylalanine concentration and vice versa.

t After adjusting for birth weight, gestational age, sex, Apgar score at five minutes, and days of ventilation.

plasma phenylalanine concentrations greater than $150 \mu \mathrm{mol} / 1$ had the lowest TE:PE ratios. Energy intake was similar in each group; the protein intake was lowest in the group with the highest TE:PE ratio (table 4). These protein and energy intakes do not include the relatively small amount of concomitant enteral feed consumed by some of the infants. Our data could indicate that high TE:PE ratios reduced the possibility of high plasma phenylalanine concentrations or, alternatively, that this relation might be coincidental as the infants with the lowest peak plasma phenylalanine concentrations were those who had the lowest protein intake. To explore this regression analysis was used to relate the TE:PE ratio to the peak plasma phenylalanine concentration (dependent variable) while adjusting for protein intake. Although the TE:PE ratio remained significantly related to the peak plasma phenylalanine concentration, the protein intake within the range studied (1.0-3.6 g/day) had no independent relation with plasma phenylalanine $(p=0 \cdot 8)$.

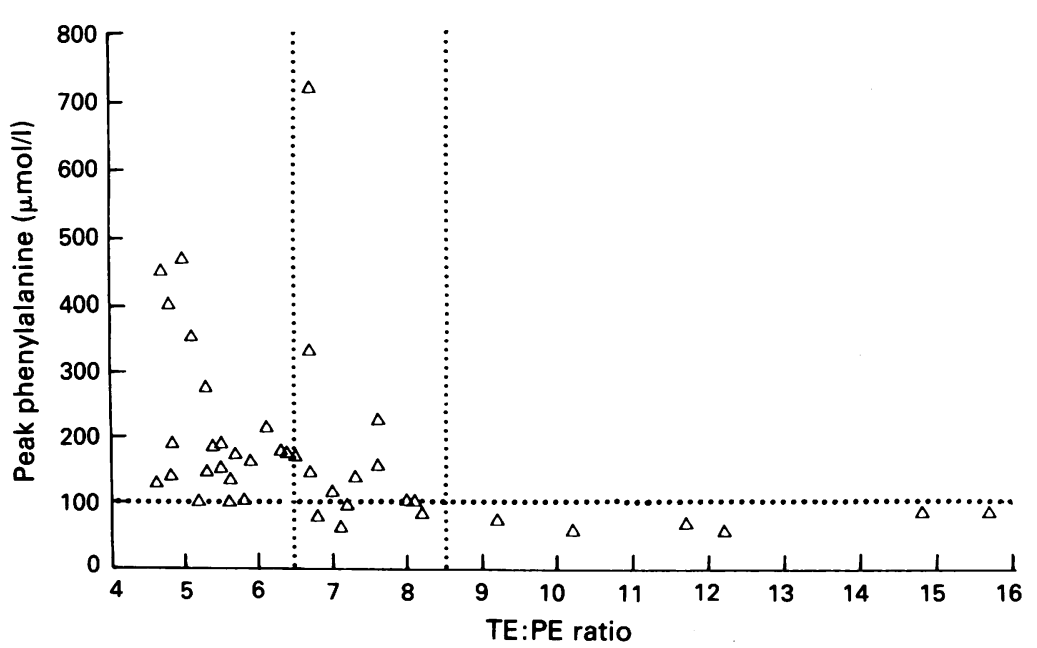

Peak plasma phenylalanine concentration and TE:PE ratio from intravenous feeding in the preceding 72 hours.
In the figure, individual peak plasma phenylalanine concentrations are plotted against the TE:PE ratio. None of the seven infants who had intake ratios greater than 8.5 had peak phenylalanine concentrations greater than 100 $\mu \mathrm{mol} / \mathrm{l}$; of those 22 infants who had ratios less than $6 \cdot 5$, all had a peak plasma phenylalanine concentration greater than $100 \mu \mathrm{mol} / 1$ (95th centile for reference data).

The relation between peak neonatal phenylalanine concentration and developmental outcome at 18 months corrected age was explored in a number of regression models, in each instance adjusting for birth weight, gestation, sex, and days of ventilation. Phenylalanine was treated (i) as a continuous variable, (ii) as a continuous variable log transformed, or (iii) as a dichotomous variable using different cut off values (above and below $100 \mu \mathrm{mol} / \mathrm{l}$ (95th centile for reference data), $150 \mu \mathrm{mol} / 1$ (99th centile), or $200 \mu \mathrm{mol} / 1$ (top of the reference range)). In none of these analyses was there any relation with the Bayley developmental indices, subscales of mental development, or with the social maturity quotient. A further analysis showed no relation between developmental outcome and duration of hyperphenylalaninaemia (weeks of recorded value greater than 100,150 , or $200 \mu \mathrm{mol} / \mathrm{l})$. As an example of this lack of a relation, table 5 shows data for the models relating peak plasma phenylalanine, as a continuous variable, to developmental scores. Of the 66 infants followed up at 18 months who received Vamin, five (8\%) had maximum phenylalanine concentrations greater than $300 \mu \mathrm{mol} / \mathrm{l}$, a value above which developmental scores have been shown to be progressively affected in phenylketonuria. ${ }^{6}$ When these five infants, whose peak plasma phenylalanine concentration was in the range 327-539 $\mu \mathrm{mol} / 1$, were compared with the remaining infants who received Vamin, the mean mental development index (unadjusted) was the same at 91.4 (SE 10.1) v 92.5 (3.0), respectively; motor scores were higher, though not significantly, in the group with high phenylalanine concentrations $(96.6(8.4) v$ $88 \cdot 0(2 \cdot 3))$.

\section{Discussion}

This study confirms that infants fed intravenously with the amino acid solution Vamin 9 often have increased plasma phenylalanine concentrations compared with the reference values we and others ${ }^{12}$ have derived. These high values may be the result of the low TE:PE ratios often used at the time when the infants were undergoing neonatal intensive care (1982-5). Nevertheless, even when infants had increased plasma phenylalanine concentrations, these could not be shown to relate to impaired mental development, motor development, or social maturity at a corrected age of 18 months.

Smith and Beasley showed that developmental outcome in children with phenylketonuria was linearly related to the mean phenylalanine concentrations all the way down to less than $300 \mu \mathrm{mol} / \mathrm{l}$, the lowest values 
achievable. ${ }^{6}$ Of the infants who received Vamin 9 who we followed up at 18 months about $8 \%$ had sustained values above this (highest $539 \mu \mathrm{mol} / \mathrm{l}$ ); it has been suggested, by analogy with phenylketonuria, that the high concentrations of phenylalanine in Vamin 9 might result in neurological damage, perhaps especially in the preterm infant who is undergoing extremely rapid brain growth. ${ }^{5}$ In phenylketonuria, however, increased plasma phenylalanine concentrations occur in isolation, competing with other neutral amino acids for the carrier mechanism across the blood-brain barrier such that the cerebral uptake of phenylalanine is likely to be greatly increased and the uptake of a number of other amino acids considerably decreased (for instance, that of methionine, histidine, isoleucine, tryptophan, threonine, and tyrosine). ${ }^{1314}$ Indeed, it has been suggested that cerebral damage in phenylketonuria might be due, at least in part, to cerebral deprivation of such amino acids. ${ }^{13}$ The pattern of change in amino acids in intravenously fed infants is different to this; increased plasma phenylalanine is associated with the concomitant increase of a number of other amino acids, for instance tyrosine. ${ }^{515}$ There have been no published data which indicate that Vamin 9 causes either an alteration in the brain fluxes of phenylalanine or adverse changes in neurodevelopment. In this study careful examination of follow up data on 278 infants, monitored sequentially for plasma phenylalanine in the newborn period, did not show that increased phenylalanine concentrations had any impact either on global tests of mental performance, motor performance, and social maturity, or on more specific subscales of the Bayley scale including language, fine motor, and cognitive development. Currently these infants are being assessed as 7.5-8 years for neurocognitive function and it will be important to confirm whether the lack of outcome disadvantage for hyperphenylalaninaemia is also found at this age.

Our data indicate that when increased plasma phenylalanine concentrations occurred, the TE:PE ratio in the intravenous feeding solution was low; indeed, all infants studied who had a TE:PE ratio of less than $6 \cdot 5: 1$ had peak plasma phenylalanine concentrations above the 95 th centile $(100 \mu \mathrm{mol} / \mathrm{l})$ for our reference range. More detailed analysis suggested that it was the ratio of total energy to protein consumed rather than the absolute level of protein intake that was predictive of plasma phenylalanine. Interestingly, Clark et $a l,{ }^{15}$ working in a unit that took care to provide a high energy to protein ratio for intravenously fed preterm infants, found that hyperphenylalaninaemia was less common than reported previously. Although we have not shown adverse consequences of increased phenylalanine concentrations with Vamin 9, it seems prudent to plan intravenous feeding regimens that avoid such increases and optimise amino acid utilisation. The data presented here (see figure) indicate that the chance of increased phenylalanine concentrations is minimised when the TE:PE ratio is greater than $8 \cdot 5: 1$, which corresponds to a suggested minimum energy intake of $34 \mathrm{kcal}(142 \mathrm{~kJ}) / \mathrm{g}$ protein.

This guideline value of $8 \cdot 5: 1$ for the ratio of TE:PE corresponds to a protein energy intake approaching $12 \%$ of the total dietary energy. When the infants were placed on enteral feeds they received one or more of the following: human milk providing only $6 \%$ of the total energy as protein, a standard 'term' formula providing $8.5 \%$, or a preterm formula providing $10 \%$ of energy as protein and designed to meet the high protein needs of the preterm infant. Most of the intravenously fed infants in this study, however, had protein energy intakes substantially in excess of this. It is, perhaps, not surprising that hyperphenylalaninaemia occurred in all the infants studied when the percentage of protein energy exceeded $15 \%$ (TE:PE 6.5:1). Furthermore, one of seven infants shown in the figure had a protein energy intake in excess of $20 \%$ of the total energy intake. These calculations emphasise that it is possible to devise intravenous feeding regimens which can, and often do, provide grossly unphysiological protein energy ratios that would not be encountered with normal foods.

New amino acid solutions designed specifically for use in infancy have now been introduced. Each new solution is based on an assumed 'ideal' biological model; for instance, the breast fed infant, the fetus, or the breast milk fed preterm infant. 1617 The superiority of any of these biological models has yet to be shown by conclusive outcome trial. Nevertheless, the data of McIntosh and Mitchell ${ }^{5}$ using one of these new solutions (MB233G, Cernap Synthelabo) and our own (unpublished) data on another (Vamin Infant, Kabi) show that plasma phenylalanine concentrations in intravenously fed newborn infants can be reduced compared with those seen with Vamin 9. Our data suggest that attention to the TE:PE ratio in intravenous feeding regimens could result in a substantially reduced risk of hyperphenylalaninaemia. For infants who sustained high plasma concentrations of phenylalanine while receiving Vamin 9, however, our developmental data at this stage in our follow up programme, reassuringly, do not provide any evidence of impaired outcome.

We thank the staff of the neonatal units in Cambridge, Ipswich, Kings Lynn, Norwich, and Sheffield; Farley Health Products for their financial assistance and continuing collaboration; and Dr Mark Gibberson, Dr Alison Hunter, and Dr Rosemary Edwards for their assistance with the follow up of infants in Sheffield; and Evelyn Smith for preparation of the manuscript.

1 Puntis JWL, Edwards MA, Green A, et al. Hyperphenylalaninaemia in parenterally fed newborn babies. Lancet 1986; ii: $1105-6$.

2 Walker V, Hall MA, Bulusu S, Allan A Hyperphenylalaninaemia in parenterally fed newborn infants. Lancet 1986; ii: 1284 .

3 Evans SJ, Wynne-Williams TCJE, Russell CA, Fairbrother A. Hyperphenylalaninaemia in parenterally fed newborn A. Hyperphenylalaninaemia in par

4 Bjorkman $O$, Lindholm $M$. Phenylalanine content and total parenteral nutrition. Lancet 1987; i: 1311 .

5 McIntosh N, Mitchell V. A clinical trial of two parenteral nutrition solutions in neonates. Arch Dis Child 1990; 65: nutrition.

6 Smith I, Beasley M, Ades AE. Intelligence and quality of dietary treatment in phenylketonuria. Arch Dis Child 1990; 65: 472-8. 
7 Lucas A, Gore SM, Cole TJ, et al. A multicentre trial on feeding low birthweight infants: effects of diet on early growth. Arch Dis Child 1984; 59: 722-30.

8 Lucas A, Morley R, Cole TJ, et al. Early diet in preterm babies and developmental status at 18 months. Lancet babies and developmental status at 18 months. Lancet 1990; 335: 1477-81.

9 Bayley N. Bayley scales of infant development. New York: The Psychological Corporation, 1969.

10 Reuter J, Stancin T, Craig PI. The Kent scoring adaptation of the Bayley scales of infant development. Ohio: Kent Developmental Metrics, 1981

11 Doll EA. Vineland social maturity scale. Circle Pines, Minnesota: American Guidance Service, 1965.

12 Rigo J. Contribution a l'etude de l'apport optimal en acides enterale. Liège: University of Liège, 1980: 1-24.
13 Pratt OE. A new approach to the treatment of phenylketonuria. f Ment Def Res 1980; 24: 203-17.

14 Partridge WM. Phenylalanine transport at the human blood-brain barrier. In: Wurtman RJ, Retter-Walker E, eds. Dietary phenylalanine and brain function. Boston: Birkhauser, 1988: 55-62.

15 Clark D, Henderson M, Smith M, Dear PRF. Plasma amino acid concentrations in parenterally fed preterm infants. Arch Dis Child 1989; 64: 939-42.

16 Rigo J, Senterre J, Putet G, Salle B. A new amino acid solution specially adapted to preterm infants. Clinical Nutrition 1987; 6: 105-9.

17 Heird WC, Hay W, Helms RA, Storm MC, Kashyap S, Dell RB. Pediatric parenteral amino acid mixture in low birthweight infants. Pediatrics 1988; 81: 41-50. 